\title{
LITERATURA INFANTO-JUVENIL BRASILEIRA: O ENSINO BÁSICO EM SÃO PAULO E AS RELAÇÕES ÉTNICO-RACIAIS
}

Maurício Silva*

Sandra Gomes**

\begin{abstract}
Resumo: O presente artigo trata das possíveis relações entre a literatura infanto-juvenil brasileira contemporânea e a questão das relações étnico-raciais, destacando aspectos relacionados à crítica à discriminação racial e combate ao racismo, bem como à representação da personagem afro-descendente nesta produção literária. Baseando-se em conceitos propostos por Munanga (2005) e Imbernón (2011), elabora-se uma discussão que pressupõe um agenciamento resultante da conscientização da identidade negra, discutida no contexto normativo da Lei 10.639/03. Além de referências a e análises de obras literárias para o público infantil, escritas no escopo temático deste trabalho, foram pesquisadas, para este estudo, quatro escolas sediadas na cidade de São Paulo, tendo sido aplicado um questionário, contendo quinze perguntas, a sessenta professores da Educação Básica da rede pública e privada.
\end{abstract}

Palavras-chave: Literatura infanto-juvenil. Relações étnico-raciais. Racismo. Lei 10.639/03. Educação básica.

\begin{abstract}
This article discusses the possible relationships between contemporary Brazilian children's literature and ethnic and racial relations, highlighting aspects not only about racial discrimination, but also about the contribution of African culture to the Brazilian culture and history. Based on Munanga (2005) and Imbernón (2011), this discussion points out the importance of the Law 10.639/03, in the Brazilian educational context. For this study, besides the analysis of some children's literature, four schools located in the city of São Paulo were surveyed. Fifteen questions were asked to sixty teachers from both public and private schools in Basic Education.
\end{abstract}

Keywords: Children's literature. Ethnic-racial relations. Racism. Law 10.639/03. Basic education.

\section{Introdução}

$\mathrm{O}$ encontro entre a literatura infanto-juvenil e as relações étnico-raciais resulta num complexo conjunto de manifestações artístico-literárias, que engloba desde obras que tematizam o universo da cultura africana e afro-brasileira ou que abordam o preconceito racial diante a realidade social contemporânea, até obras que tratam da escravidão e suas representações, da identidade negra e da diversidade cultural do Brasil, entre outras. Essa discussão pode-se adensar ainda mais se levarmos em consideração a dificuldade de caracterizaração dessa literatura, que para a crítica especializada se define ora como uma literatura negra, ora como afro-brasileira, ora ainda como afro-descendente (SOUZA; LIMA, 2006). De qualquer maneira, independentemente da "divisão" que se faça da produção literária infanto-juvenil vinculada às questões étnico-raciais e da "definição" que suas diversas manifestações podem assumir, o fato é que essa produção - ao se associar às noções de multiculturalismo e pluralidade étnica - não prescinde de um agenciamento que resulta numa conscientização da identidade negra, por isso mesmo não apenas inserindo-se no contexto normativo da lei 10.639/03, mas principalmente numa ampla discussão histórica da formação da sociedade brasileira.

Ao se pensar analisar essa produção, percebe-se, por exemplo, que, embora a figura do negro continue pejorativamente marcada no imaginário brasileiro, gerando preconceitos

\footnotetext{
* Doutor em Letras Clássicas e Vernáculas pela Universidade de São Paulo. Professor do Programa de PósGraduação em Educação da Universidade Nove de Julho, São Paulo, SP - Brasil. Endereço eletrônico: maurisil@gmail.com

** Mestranda em Educação pela Universidade Nove de Julho, São Paulo, SP - Brasil, sob orientação do Prof. Dr. Maurício Silva. Endereço eletrônico: san.r.gomes@ hotmail.com
} 
diversos, há atualmente uma produção literária infanto-juvenil que já aponta para um movimento de transformação desse padrão, com a publicação de obras que procuram valorizar a figura do afrodescendente e realçar uma identidade que se constrói a partir da diversidade. Nesse sentido, percebe-se um caminhar na direção da construção de uma literatura mais condizente com a realidade contemporânea, mas sem deixar de lado uma perspectiva crítica que, por isso mesmo, denuncia atos de discriminação implícita ou explícita, ainda presentes em nossa produção literária para crianças e jovens, reflexo mais evidente e direto de uma sociedade excludente, como é a sociedade brasileira. O presente artigo trata das possíveis relações entre a literatura infanto-juvenil brasileira contemporânea e a questão das relações étnico-raciais, destacando aspectos relacionados à crítica à discriminação racial e combate ao racismo, bem como à representação da personagem afro-descendente nesta produção literária. Para tanto, além de considerações analíticas de obras que abordam as temáticas aqui destacadas, direta ou indiretamente relacionadas ao universo das questões étnico-raciais, foram pesquisadas quatro escolas sediadas na cidade de São Paulo, tendo sido elaborado um questionário com quinze perguntas, aplicado a sessenta professores da Educação Básica da rede pública e privada.

\section{Relações étnico-raciais no contexto da educação brasileira e a literatura infanto- juvenil}

A legislação voltada às questões étnico-raciais no Brasil não é nova, embora sua aplicação tenha sido prejudicada por uma série de percalços, que vão do histórico preconceito que impera na sociedade brasileira à impedimentos de natureza jurídica e afins. Especificamente sobre a educação das relações étnico-raciais, há uma legislação específica aprovada, e os direitos da população negra (embora não apenas dela) passaram a ser garantidos pela Lei de Diretrizes e Base da Educação Nacional (LDB), que estabelece, entre outras perspectivas, o respeito aos valores culturais na educação e repúdio ao racismo, na medida em que determina o estudo das e o respeito às contribuições das diferentes culturas e etnias para a formação do povo brasileiro. Semelhante determinação acabaria resultando naquela lei que, mais do que qualquer outra, incide diretamente sobre a importância da contribuição das matrizes culturais próprias da população afrodescentende: trata-se da Lei 10.639, sancionada em 09 de janeiro de 2003, por meio da qual se torna obrigatório, no Ensino Fundamental e Médio, o ensino sobre História e Cultura Afro-Brasileira, o que assinala a necessidade do estabelecimento de novas diretrizes curriculares nacionais para a educação das relações étnico-raciais no Brasil.

$\mathrm{O}$ encontro entre a literatura infanto-juvenil e as relações étnico-raciais resulta num complexo conjunto de manifestações artístico-literárias que França (2008) subdividiu da seguinte maneira: obras que tematizam o universo da cultura africana e afro-brasileira; obras que tematizam o preconceito racial diante a realidade social contemporânea; obras que tematizam a escravidão; obras que tematizam a identidade negra e a diversidade cultural do Brasil; e obras que, sem abordar diretamente a questão racial, apresentam o negro como personagem literária, em situação de igualdade com os outros personagens. Seu quadro exprime bem a diversidade de perspectivas que podem ser adotadas para se tratar da conjunção entre a literatura infanto-juvenil e as relações étnico-raciais, revelando o quanto semelhante abordagem pode ser rica e complexa. Diante do quadro exposto, contudo, ainda caberia perguntar: qual a natureza - e, por extensão, quais as propriedades, as idiossincrasias, os elementos determinantes - de uma literatura infanto-juvenil especialmente vinculadas seja pela temática, seja pela autoria, seja ainda pela ideologia veiculada - à questão étnicoracial? 
Pesquisas acadêmicas ou não, voltadas para a presença da temática negra nas obras de literatura infanto-juvenil brasileira podem nos apontar o caminho para uma resposta minimamente satisfatória. Em seu já clássico estudo sobre o perfil ideológico dessa literatura no período de 1955 a 1975, Rosemberg (1985), analisando 168 livros infanto-juvenis brasileiros (num total de 626 histórias), detecta, entre outros aspectos, um tratamento diferenciado - que, no entanto, aparece de forma aberta ou velada - dado a brancos e negros. Assim, segundo seu estudo, personagens mais frequentes nos textos e nas ilustrações, os brancos são também representados como modelos da espécie humana, apresentando atividades profissionais mais diversificadas, recebendo melhor acabamento estético, representando figuras e personagens históricos mais relevantes etc. (1985), o que pode resultar, por fim, não apenas na instauração de um processo discriminatório de fato, mas de uma violência simbólica (LIMA, 2005). Ao se pensar nessa questão de forma similar, mais de duas décadas depois, percebe-se, por exemplo, que, embora a figura do negro continue pejorativamente marcada no imaginário brasileiro, gerando preconceitos diversos, há atualmente uma produção literária infanto-juvenil que já aponta para um movimento de transformação desse padrão, com a publicação de obras que procuram valorizar a figura do negro e realçar uma identidade que se constrói a partir da diversidade (KNOP, 2010). Percebe-se, portanto, uma diferença significativa, que acusa - inclusive quantitativamente (DEBUS, 2007; DEBUS;VASQUES, 2009) - um caminhar na direção da construção de uma literatura mais condizente com a realidade atual, mas sem deixar de lado uma perspectiva crítica que, por isso mesmo, denuncia atos de discriminação implícita ou explícita, ainda presentes em nossa produção literária infanto-juvenil.

Buscando, portanto, responder em parte o questionamento feito acima, acerca dos vínculos entre a literatura infanto-juvenil e questões de natureza étnico-racial, partimos, antes de mais nada, do princípio de que, como já se afirmou mais de uma vez (SILVA, s.d.), assumir/incluir posicionamentos éticos nos textos literários para crianças e jovens especialmente voltados para as relações étnico-raciais - não significa limitar o potencial estético das obras. A partir desse ponto de vista, não hesitamos em afirmar que a literatura infanto-juvenil direta ou indiretamente vinculada às relações étnico-raciais pauta-se ou deve pautar-se por atitudes de valorização da cultura afro-brasileira, de estímulo à (re)construção de uma identidade afro-descendente, de resgate da autoestima, dos valores culturais, dos direitos, da memória e da identidade do negro, desfazendo injustiças seculares e ressemantizando o conceito de negritude a partir de um agenciamento afro-brasileiro, atitudes, por fim, norteadas pelos princípios genéricos de multiculturalismo e pluralidade étnica, antes citados.

Há, na vasta produção literária brasileira voltada para crianças e jovens, em especial naquelas que procuram destacar/explorar motivos de extração étnico-racial, alguns temas recorrentes que, por sua própria natureza, contribuem para uma mais intensa e profunda reflexão sobre o lugar que o negro ocupa em nossa sociedade atualmente. Trata-se, antes de mais nada, de textos que, senão pela posição pessoal que seus autores ocupam/assumem diante do campo literário, pelo menos pela temática que abordam com maior ou menor grau de explicitação, inserem-se na ou pelo menos dialogam com aquelas obras e autores em que Eduardo Duarte detectou um deliberado pertencimento étnico (DUARTE, 2013).

É o que se pode verificar nos mais diversos títulos, que discutem desde questões relativas a traços fisionômicos e/ou fenotípicos do afrodescendente - como Menina Bonita do Laço de Fita (2000), de Ana Maria Machado; O círculo (1985), de Maria Lysia Corrêa de Araújo; ou O herói de Damião (A descoberta da capoeira) (2000), de Isa Lolito -, passando por discussões acerca da questão racial propriamente dita - com Irmão Negro (1995), de Walcyr Carrasco; Felicidade não tem cor (1997) e Pretinha, eu? (2008), de Júlio Emílio Braz; ou O amigo do rei (1999), de Ruth Rocha - até temas mais contundentes e polêmicos, 
como o da negritude, do racismo e do preconceito - por exemplo, em A cor da ternura (1989), de Geni Guimarães; em $O$ sol da liberdade (1985), de Giselda Laporta Nicolelis; ou em Os bons e os justos (A fábula do amor bastardo) (1983), de Lourenço Cazarré.

\section{Literatura infanto-juvenil brasileira e relações étnico-raciais no Ensino Básico}

Após mais de um século abolição de escravatura, acredita-se, ingenuamente, que os problemas de racismo e preconceito no Brasil já foram sumariamente superados. Essa realidade, contudo, continua vigindo de forma quase irretocável, como se pode constatar em qualquer análise da questão educacional brasileira, de cujo sistema excludente o contingente afrodescendente é vítima. Com o intuito de realizar uma ruptura no ciclo que perpetua o racismo no âmbito da educação, foi criada a Lei 10.639/03, como uma importante forma de reparação de uma divida social.

Amparada por esta referida lei, a experiência aqui relatada é resultado de uma pesquisa que buscou observar a relação entre o profissional da Educação Básica, a literatura e a referida lei. O método utilizado consistiu na aplicação de um questionário a 60 professores da Educação Básica da Rede Pública e Privada do Estado de São Paulo. Durante o período de aplicação do questionário, também foi possível conhecer as dependências das instituições, aceder a alguns documentos institucionais, ter contato com as crianças e até mesmo conversar com coordenadores e demais funcionários das instituições de ensino visitadas, o que permitiu uma maior explanação acerca de cada uma especificamente.

A primeira instituição visitada foi um Centro de Educação Infantil (CEI), localizado na Zona Oeste de São Paulo - precisamente na Avenida Pacaembu, região nobre de São Paulo - e mantido por uma Sociedade de Defesa e Apoio às Comunidades Urbanas, uma associação de utilidade pública, sem fins lucrativos, conveniada à Prefeitura do Município de São Paulo, através da Secretaria Municipal de Educação, conforme exigido pela legislação. A maioria das crianças que frequentam o CEI é formada por filhos dos empregados dos estabelecimentos locais, porém a mesma instituição também atende a uma clientela de maior poder aquisitivo, filhos de donos de consultórios médicos e pequenos comércios da região, promovendo assim um interessante convívio social entre diversas classes sociais.

Esse CEI oferece atendimento a crianças de 0 a 4 anos de idade, em um trabalho de cooperação e articulação da rede pública e privada de serviços, atendendo às necessidades e características de desenvolvimento da criança ali inserida no período das 7 às 17 horas, de segunda a sexta-feira, contando com aproximadamente 180 crianças, divididas em: berçário I, com 2 salas e 7 crianças cada, onde ficam os bebês de 0 a 1 ano de idade; berçário II, com 4 turmas de 9 alunos cada, atendendo a crianças de 1 a 2 anos de idade; 5 turmas de mini grupo I, atendendo a crianças de 2 a 4 anos de idade; e 1 mini grupo II, para as crianças com 4 anos de idade, mas que ainda não foram transferidas para o pré, devido à data em que completam a idade requerida. Para atender a esse alunado, atualmente o CEI conta com o trabalho da diretora, auxiliar de direção, aproximadamente 13 professores e 6 auxiliares, entre cozinheiras, auxiliares de cozinha, professora de balé e judô, além do serviço prestado por alguns voluntários que contribuem para o bom funcionamento da creche.

A segunda instituição visitada foi uma Escola Municipal de Educação Infantil (EMEI), criada pelo Decreto $\mathrm{n}^{\circ} 38.689$, de 25/11/1999, anteriormente regida pelo Decreto Municipal no 37.205, de 08/12/1997. Localizada na Praça Coronel Ezequiel, no bairro de Vila Silvia, distrito de Cangaíba, Zona Leste, na cidade de São Paulo e vinculada à Coordenadoria de Educação Penha, pertencente à Subprefeitura Penha. Conforme o exposto pela equipe diretiva da instituição, a escola surgiu devido a reivindicações da comunidade aos políticos da região, pois se trata de uma área que apresentava grande número de crianças na faixa etária 
entre quatro e seis anos de idade, resultado do permanente crescimento populacional do bairro.

A equipe escolar é representada por um expressivo quadro, sendo composta por: equipe técnica, representada pela diretora e coordenadora pedagógica; equipe docente, representada por 21 professores; equipe de apoio à educação, representada por agentes escolares e agentes de apoio e limpeza.

Conforme dados extraídos do Projeto Pedagógico da Instituição, o alunado atendido pela escola apresenta-se bastante diversificado, composto principalmente por crianças que moram em favelas próximas e outros tipos de residências, sendo que mais ou menos metade possui residência própria; além disso, a maior parte desse contingente mora no bairro há mais de 5 anos, tendo alguns pais indicado que residem na região desde o nascimento. A maioria dos pais ou responsáveis apresenta um grau de escolaridade compatível com o ensino fundamental, tendo, uma boa porcentagem, concluído o ensino médio, com alguns casos mais raros em que concluíram o ensino superior; a renda média dessas famílias varia entre 1 e 3 salários mínimos.

Quanto à Proposta Pedagógica, é possível destacar dentre seus princípios a valorização do direito de a criança brincar, como forma particular de expressão, pensamento, interação e comunicação infantil, buscando alicerçar os pressupostos das teorias existentes com a prática social ligada à realidade da escola e de sua clientela, distinguindo entre seus objetivos a importância de a criança conhecer algumas manifestações culturais, demonstrando atitudes de interesse, respeito e participação frente a elas e valorizando a diversidade.

A terceira instituição visitada foi uma Escola Municipal de Ensino Fundamental (EMEF), uma instituição de utilidade pública, sem fins lucrativos, conforme consta na legislação; ela está situada na Rua Manoel Dias do Campo, no Bairro da Casa Verde Alta, Zona Norte de São Paulo.

Segundo registro de pesquisas realizadas pela escola em 2015, a comunidade é composta de famílias de quatro a sete pessoas, com as seguintes peculiaridades: $40 \%$ dos pesquisados são de estado civil solteiro; 69\% são de São Paulo e 5\% são formados por imigrantes bolivianos; $45 \%$ são pardos e 14\%, negros; a escolaridade do responsável por alunos fica entre o ensino fundamental e médio; $21 \%$ não estão empregados; a renda familiar de $32 \%$ concentra-se entre $\mathrm{R} \$ 200,00$ e $\mathrm{R} \$ 780,00 ; 30 \%$ recebem auxílio da bolsa família; $56 \%$ dos alunos ficam sozinhos, enquanto o responsável trabalha fora; $22 \%$ participam de centros de convivência e $22 \%$ fazem cursos e esportes; $89 \%$ são usuários do SUS.

A EMEF oferece atendimento a crianças e adolescentes de 6 a 14/16 anos de idade, em um trabalho de cooperação e articulação da rede pública e privada de serviços, atendendo às necessidades e características de desenvolvimento da criança e adolescente inseridos na unidade escolar no primeiro (das 7 às 12 horas), no segundo (das 13 às 18 horas) e no terceiro períodos (das 18:30 às 20:30 horas), de segunda a sexta-feira, tendo hoje aproximadamente 763 alunos, divididos em: período da manhã e período da tarde. Para atender a esta clientela, atualmente a EMEF conta com o trabalho da diretora, duas assistente de direção, aproximadamente 60 professores e 13 módulos, agentes escolares, agentes de apoio, cozinheiras e auxiliares de cozinha.

Dentre os principais objetivos da Proposta Pedagógica, é possível destacar que a EMEF afirma-se como um espaço coletivo e privilegiado de vivência da infância e adolescência, que busca sensibilizar a comunidade escolar, pais, alunos, docentes, funcionários operacionais, equipe técnica e de apoio para a construção de um ambiente escolar colaborativo e para o desenvolvimento do processo ensino-aprendizagem: desenvolvimento da autonomia, o protagonismo, a convivência harmoniosa, respeito étnicoracial e aos alunos com necessidades especiais.

A quarta e última instituição visitada difere muito dos demais, tanto 
arquitetonicamente, quanto em sua organização administrativa e pedagógica, além da clientela atendida. Localizado no bairro de Perdizes, um dos bairros mais privilegiados de São Paulo, com a maioria dos moradores formada pela classe média alta, é uma importante referência no bairro. É uma escola com quarenta anos de história, fundado pela união de irmãs da mesma família, que tinha como sonho uma escola onde se aprende brincando. Iniciou com 22 alunos e hoje possui aproximadamente 3000, divididos entre as unidades de Perdizes, Morumbi e Alphaville.

A unidade de Perdizes, objeto desta pesquisa, tem aproximadamente 1153 alunos e aproximadamente 100 professores. A escola encontra-se instalada num prédio antigo, onde, anteriormente, ficava um convento de freiras, tendo sido tombado pelo poder público, com o intuito de preservar, por meio de legislação específica, seu valor cultural, arquitetônico e histórico. Além dos espaços destinados a parte pedagógica, como salas de aulas, salas de apoio e sala interdisciplinares, também dispõe de uma extensa parte administrativa, dividida em: secretaria escolar, sala da diretoria, coordenação administrativa, departamento de uniformes, relações institucionais, gráfica própria; enfermaria; sala de reunião e atendimento aos pais, dentre outras.

Conforme apontado anteriormente, o método utilizado nesta pesquisa consistiu na aplicação de um questionário, contendo 15 perguntas, a 60 professores da Educação Básica da Rede Pública e Privada do Estado de São Paulo. Voltado para a área da literatura infantil brasileira, seu objetivo principal foi coletar dados relativos às questões étnico-raciais na escola e analisá-los. Segundo Gil (2010), o questionário é uma técnica de investigação que serve para coletar dados de cunho empírico, com um número razoavelmente elevado de questões, na qual se busca conhecer principalmente a opinião das pessoas sobre determinados assuntos, tendo como uma de suas vantagens garantir o anonimato de quem participa.

A participação dos professores foi voluntária, e a divisão por escola visitada ficou da seguinte forma: no Centro de Educação Infantil, localizado na zona oeste/SP, 7 professores responderam ao questionário; na Escola Municipal de Educação Infantil, localizada na Zona Leste/SP, 14 professores participaram da pesquisa, dentre os quais contamos com a participação e colaboração da coordenadora pedagógica; na Escola Municipal de Ensino Fundamental, da Zona Norte/SP, 28 professores se propuseram a responder, e também contamos com a participação e apoio da coordenadora pedagógica; na instituição privada, de ensino fundamental, situada na Zona Oeste/SP, 11 professores participaram respondendo a pesquisa.

As perguntas apresentadas foram de cunho empírico, e serviram para coletar informações condizentes com o pensamento e opinião dos profissionais que se dispuseram a participar da referida pesquisa, tendo sido as mesmas basilares para a construção deste artigo. Dentre as 15 perguntas que compuseram a pesquisa, 14 foram perguntas fechadas, que traziam alternativas específicas para que o docente escolhesse a resposta, e uma pergunta foi aberta. Como sugerido inicialmente, o questionário buscou resposta a diversos aspectos da realidade, em consonância com a Lei 10.639/03. A pesquisa, portanto, buscou observar a relação entre o profissional da educação básica, a literatura infanto-juvenil e a referida lei. Desse modo foram explorados aspectos como: o conhecimento dos professores sobre a lei e sua utilização na proposta curricular das instituições onde lecionam; a formação continuada desses profissionais, já que, de acordo com Imbernóm (2011, p. 115), "é preciso estudar como a formação permanente contribui para a profissionalização dos professores," os livros de temática africana e afro-brasileira disponíveis nas instituições onde atuam estes profissionais e sua utilização em sala de aula; a importância da literatura para o combate ao racismo nas escolas; a opinião destes professores quanto à necessidade de lei especifica da área da educação com o propósito de resistência antirracista; as recentes polêmicas em torna da obra de Monteiro Lobato; a tematização do racismo pelos professores no ambiente escolar, dentre 
outros. Tais questionamentos refletem a ideia de que, segundo Munanga,

não existem leis no mundo que sejam capazes de erradicar as atitudes preconceituosas existentes nas cabeças das pessoas, atitudes essas provenientes dos sistemas culturais de todas as sociedades humanas. No entanto, cremos que a educação é capaz de oferecer tanto aos jovens como aos adultos a possibilidade de questionar e descontruir os mitos de superioridade e inferioridade entre grupos humanos que foram introjetados neles pela cultura racista na qual foram socializados. (MUNANGA, 2005, p. 17).

Após cuidadosa análise dos dados, buscamos destacar aqui alguns resultados encontrados, dentre os que revelaram mais importância para a reflexão que vimos fazendo até aqui.

$\mathrm{O}$ primeiro resultado da pesquisa assinalou que $50 \%$ dos professores que responderam ao questionário consideram a sociedade brasileira racista e $46 \%$ acreditam que nossa sociedade é um pouco racista; $85 \%$ afirmam ter conhecimento da Lei 10.639/03, que visa à obrigatoriedade do ensino de história e cultura africana e afro-brasileira nos ensinos fundamental e médio, porém apenas $16 \%$ conhecem a lei que trata sobre a literatura africana ou afro-brasileira; e ainda $60 \%$ acreditam não ser necessária uma lei específica para abordar esse relevante tema.

Ao refletir a cerca destes percentuais encontrados é possível aferirmos que um expressivo percentual de professores participantes da pesquisa reconhece e identifica a desigualdade racial, pois considera a sociedade brasileira racista ou um pouco racista; contudo, não relaciona essa desigualdade racial à discriminação e ao preconceito, pois ignora, desconhece ou até mesmo desaprova a lei que aborda o tema.

Para melhorar compreensão dos resultados, procuramos dar continuidade na análise realizada e percebemos que $55 \%$ dos professores afirmam não ter obtido uma formação continuada alusiva à referida lei; $52 \%$ dizem ter conhecimento de que a biblioteca da escola possui literatura relativa ao tema e 50\% dizem que esses livros não são usados em sala de aula; $94 \%$ acreditam que a literatura é um meio de combater o racismo; no entanto, $48 \%$ não respondeu que obra utiliza e 35\% citaram Menina bonita do laço de fita.

Ainda na mesma linha reflexiva, parece evidente que esses profissionais, carecem de formação específica voltada ao conhecimento da referida lei. Faz-se necessária a formação sólida do profissional da educação, da graduação à formação continuada, a fim de se garantir as bases necessárias para se tratar as relações étnico-raciais dentro da escola, onde a literatura pode e deve ser uma aliada eficaz, uma vez que apenas a implantação e a obrigatoriedade desses temas, por força da lei, não surtem os resultados almejados.

Em continuidade com a pesquisa e com as ponderações acerca do questionário, sublinhamos que $67 \%$ afirmam ter se confrontado (e mediado o conflito) com algum tipo de racismo contra negros dentro do ambiente de sala de aula; e 33\% dizem não ter encontrado/mediado situação de racismo. Neste caso, inferimos pela presença, no ambiente escolar, de um racismo declarado, um tipo de racismo cordial, capaz de encobrir posicionamentos racistas e preconceituosos.

Por fim, não podemos deixar de lembrar o que foi respondido a cerca de Monteiro Lobato e sua obra ser ou não racista: $49 \%$ dizem não considerar as obras de Lobato racistas e $39 \%$ consideram algumas obras racista, sendo que $6 \%$ nem sequer conhecem as obras do autor. Elucidando a dimensão da magnitude de Lobato e sua obra, analisando-o sob a perspectiva da questão étnico-racial, Lajolo (1998), afirma que: 
discutir a representação do negro na obra de Monteiro Lobato, além de contribuir para o conhecimento maior deste grande escritor brasileiro, pode renovar os olhares com que se olham sempre delicados laços que enlaçam literatura e sociedade, história e literatura, literatura e política e similares binômios que tentam dar conta do que na página literária, fica entre seu aquém e seu além. (LAJOLO, 1998, s.p.).

Com certeza, essa é uma inestimável oportunidade para que levemos para a sala de aula uma discussão mais profunda acerca das questões étnico-raciais não apenas na escola, mas em toda a sociedade. O emprego da literatura infanto-juvenil como canal de veiculação de ideias propulsoras dessa discussão é, mais do que legítimo, necessário.

\section{Considerações finais}

A literatura infanto-juvenil passou a ter uma importância incomensurável na atualidade, agindo ainda na construção da própria cidadania da criança, facilitando o diálogo e a formação de uma consciência crítica no leitor-mirim. Desse modo, tanto o educador quanto os pais têm oportunidade de trabalhar conflitos infantis a partir de histórias que estimulem o imaginário infantil, mas também que levem em conta aspectos diversos da sociedade contemporânea, como é o caso das relações étnico-raciais e os conflitos que delas resultam.

Semelhante constatação pressupõe, contudo, uma consideração mais ampla e, também, mais crítica da questão: Cardoso (2011), por exemplo, lembra que mesmo a produção infanto-juvenil brasileira contemporânea não é pródiga em trazer personagens com quem a criança afrodescendente possa se identificar, embora algumas exceções já comecem a surgir no cenário atual. E completa:

a presença de personagens negras na literatura é fundamental para todos os leitores. Se, por um lado, para a criança negra, essa mudança pode contribuir para a autoestima e o seu reconhecimento no mundo, para a branca pode ser o espaço de reconhecimento da diversidade étnica. (CARDOSO, 2011, p. 131).

A questão da identificação do leitor com personagens da literatura infanto-juvenil bem como a consideração da leitura como forma de superação de preconceitos - também é ressaltada por Barreiros, que considera que "a identificação com narrativas próximas da sua realidade e com personagens que vivem problemas e situações semelhantes as suas leva o leitor a reelaborar e se conscientizar sobre o seu papel social e contribui para a afirmação de uma identidade étnica" (2009, p. 04).

Ao refletirmos acerca das respostas encontradas, é possível inferir que, a educação no Brasil - não apenas descumpre seu papel no sentido de se opor ao e contribuir para a erradicação do racismo, mas acaba, indiretamente, reforçando-o, pois se observa, entre outro aspecto, a dificuldade que nossos profissionais da educação têm em relação a lidar com essa questão, além de desconhecerem e/ou não compreenderem a lei que, justamente, trata da valorização da cultura negra e afrodescendente, possivelmente pela falta de uma formação específica. Pode-se dizer que, embora identifiquem e reconheçam, em muitos casos, as situações de racismo e discriminação, encontram dificuldade em trazê-las para um debate dentro da escola, não promovendo, consequentemente, a tão necessária ruptura do ciclo que perpetua, em nossa sociedade, o preconceito racial. 


\section{Referências}

BARREIROS, R. C. A literatura infantil Afro-Brasileira e a Formação Leitora no Ensino Fundamental. Anais do $17^{\circ}$ Congresso de Leitura do Brasil - COLE, Campinas, Unicamp, jul. 2009, $\quad$ p. $\quad 01-09 \quad$ (http://alb.com.br/arquivomorto/edicoes_anteriores/anais17/txtcompletos/sem15/COLE_3659.pdf)

CARDOSO, R. A criança que se lê, o mundo que se percebe, o sonho que se constrói: possibilidades da inclusão étnico-racial. In: OLIVEIRA, Alexandre et al. Deslocamentos críticos. São Paulo, Itaú Cultural/Babel, 2011, p. 129-142.

DEBUS, E. S. D. A Literatura Infantil Contemporânea e a Temática Étnico-Racial: Mapeando a Produção. Anais do $16^{\circ}$. Congresso de Leitura do Brasil - COLE, Campinas, Unicamp, jul. 2007, $\quad$ p. $01-10 \quad$ (http://alb.com.br/arquivomorto/edicoes_anteriores/anais16/sem08pdf/sm08ss12_06.pdf)

DEBUS, E. S. D.; VASQUES, M. C. A linguagem literária e a pluralidade cultural: contribuições para uma reflexão étnico-racial na escola. Conjectura. Universidade de Caxias do Sul, v. 14, No. 2: 133-144, Mai.-Ago. 2009.

DUARTE, E. A. Na cartografia do romance afro-brasileiro, Um defeito de cor, de Ana Maria Gonçalves. In: ALMEIDA, J.; MIGLIEVICH-RIBEIRO, A.; GOMES, H. T. (Orgs.). Crítica Pós-Colonial. Panorama de Leituras Contemporâneas. Rio de Janeiro, 7Letras, 2013, p. 208227.

FRANÇA, L. F. de. Desconstrução dos estereótipos negativo do negro em Menina bonita do laço de fita, de Ana Maria Machado, e em O menino marron, de Ziraldo. Estudos de literatura brasileira contemporânea, Brasília, Universidade de Brasília, No. 31: 111-127, 2008. (http://seer.bce.unb.br/index.php/estudos/article/view/2022/1595)

GIL, A. C. Como elaborar Projetos de Pesquisa. São Paulo, Atlas, 2010.

IMBERNÓN, F. Formação Docente e Profissional: formar-se para a mudança e a incerteza. São Paulo, Cortez, 2011.

KNOP, R. M. Antes, era uma vez, hoje, essa é a sua vez: uma abordagem comparativa da representação social do negro na literatura para crianças. Belo Horizonte, Pontifícia Universidade Católica de Minas Gerais, 2010 (Dissertação de mestrado).

LAJOLO, M.. A figura do negro em Monteiro Lobato. Revista Brasil de Literatura. São Paulo, Ano IV, 2002, s.p. (http://lfilipe.tripod.com/lobato.htm).

LIMA, H. P. Personagens negros: um breve perfil na literatura infanto-juvenil. In: MUNANGA, K. (Org.). Superando o racismo na escola. Brasília, Ministério da Educação/SECAD, 2005, p. 101-115.

MUNANGA, K. (Org.). Superando o racismo na escola. Brasília, MEC/SECAD, 2005.

ROSEMBERG, F. Literatura Infantil e Ideologia. São Paulo Global, 1985. 
SILVA, L. M. J. e. O imaginário da inclusão na Literatura Infanto-Juvenil. Construir Notícias, Recife, s.d. (http://www.construirnoticias.com.br/asp/materia.asp?id=1044)

SOUZA, F.; LIMA, M. N. (Orgs.). Literatura Afro-Brasileira. Brasília, Centro de Estudos Afro-Orientais / Fundação Palmares, 2006.

Recebido em: maio de 2016.

Aprovado em: julho de 2016. 